Article

\title{
Antileishmanial Potential of Tropical Rainforest Plant Extracts
}

\author{
Lianet Monzote ${ }^{1}$, Abel Piñón ${ }^{1}$, and William N. Setzer ${ }^{2, *}$
}

1 Parasitology Department, Institute of Tropical Medicine "Pedro Kouri", 10400 Havana, Cuba; E-Mail: monzote@ipk.sld.cu

2 Department of Chemistry, University of Alabama in Huntsville, Huntsville, AL 35899, USA; E-Mail: wsetzer@chemistry.uah.edu

* Author to whom correspondence should be addressed; E-Mail: wsetzer@chemistry.uah.edu; Tel.: +1-256-824-6519; Fax: +1-256-824-6349.

External editor: Ronan Batista

Received: 9 October 2014; in revised form: 11 November 2014 / Accepted: 12 November 2014 / Published: 19 November 2014

\begin{abstract}
A total of 115 different plant extracts from our collection, representing 96 plant species, have been evaluated for in vitro antileishmanial activity against L. amazonensis promastigotes. In addition, the extracts were screened for cytotoxic activity against $\mathrm{BALB} / \mathrm{c}$ mouse macrophages in order to assess a selectivity index. Crude extracts that showed a selectivity index $\left(C C_{50}\right.$ for macrophage $/ I C_{50}$ for promastigotes $) \geq 5$ or with $I C_{50}<12.5 \mu \mathrm{g} / \mathrm{mL}$ against promastigotes, a total of 28 extracts, were further screened for anti-amastigote activity. A total of 25 extracts showed promising activity against L. amazonensis promastigotes with low cytotoxic activity. Ten of these extracts showed selectivity indices, $\left(C C_{50}\right.$ for macrophages / I $C_{50}$ for amastigotes) greater than 10 and are considered "hits", worthy candidates for further phytochemical exploration: Conostegia xalapensis methanol bark extract, Endiandra palmerstonii bark extract, Eugenia monteverdensis acetone bark extract, Eugenia sp. "fine leaf" acetone bark extract, Exothea paniculata chloroform bark extract, Mallotus paniculatus ethanol bark extract, Matelea pseudobarbata ethanol extract, Quercus insignis ethanol bark extract, Sassafras albidum dichloromethane bark extract, and Stemmadenia donnell-smithii acetone bark extract.
\end{abstract}

Keywords: leishmaniasis; Leishmania amazonensis; Abaco island; Bahamas; Matabeleland; Zimbabwe; Monteverde; Costa Rica; Far North Queensland; Australia 


\section{Introduction}

Leishmaniasis is a collection of chronic infectious diseases caused by different species of parasitic Leishmania protozoa and are transmitted by sandflies (Phlebotomus spp. and Lutzomyia spp.) [1,2]. The disease, considered to be a "neglected disease", currently affects around 12 million people, with nearly 350 million people at risk of infection around the world. The clinical forms of leishmaniasis have been classified as cutaneous, mucocutaneous, or visceral. Additionally, global climate change will likely affect the geographical range of Leishmania infections in North America [3] and Europe [4]. Indeed, Phlebotomus sandfly distribution in Europe has shifted as far north as Germany [5] while Lutzomyia sandflies are now found as far north as Ohio [6], Maryland, and Delaware [7].

Current proven chemotherapy includes the pentavalent antimonials meglumine antimoniate (glucantime) and sodium stibogluconate (pentostam) [8], miltefosine, amphotericin B, or pentamidine [9]. However, all of these treatments are associated with undesirable side effects, induction of parasite resistance, and relatively high cost in developing countries. Due to the limitations of current chemotherapeutic regimes, along with the absence of suitable vaccines, there is a persistent need for alternative and readily available chemotherapies for treatment of leishmaniasis.

Natural products have overwhelmingly contributed to the pharmacopeia of the world and continue to provide new and effective anti-infective agents [10-12]. Recently, several reviews have appeared demonstrating the potential of higher plants and phytochemicals as treatment options for leishmaniasis [13-19]. In this current work, we present the in vitro screening of 115 different extracts from higher plants (96 species) collected from rainforests of north Queensland, Australia, Abaco Island, Bahamas, Costa Rica, southeastern U.S., and Zimbabwe, against Leishmania amazonensis.

\section{Experimental Section}

\subsection{Plant Materials and Reference Drugs}

Plant materials from 96 species of plants (Table 1) were collected and extracted as previously described [20-22]. The crude extracts were dissolved in dimethylsulfoxide (DMSO) at $20 \mathrm{mg} / \mathrm{mL}$. The reference drugs amphotericin B (Imefa, Havana, Cuba) and pentamidine (Richet, Buenos Aires, Argentina) were also used.

\subsection{Parasite Cultures}

L. amazonensis (MHOM/77BR/LTB0016) was kindly provided by the Department of Immunology, Oswaldo Cruz Foundation (FIOCRUZ), Brazil. Parasites were routinely isolated from mouse lesions and maintained as promastigotes at $26{ }^{\circ} \mathrm{C}$ in Schneider's medium (SIGMA, St. Louis, MO, USA) containing 10\% heat-inactivated fetal bovine serum (HFBS) (SIGMA, St. Louis, MO, USA), $100 \mu \mathrm{g}$ of streptomycin $/ \mathrm{mL}$, and $100 \mathrm{U}$ penicillin $/ \mathrm{mL}$. The parasites were not used after the tenth passage.

\subsection{Anti-Promastigote Assay}

Schneider's medium $(50 \mu \mathrm{L})$ was distributed in each well of a 96-well plate. In the first well of each lane, $48 \mu \mathrm{L}$ of medium and $2 \mu \mathrm{L}$ of tested extracts were added. The extract solutions were serially 
diluted (1:1) down each lane of the 96-well plate with medium (removing $50 \mu \mathrm{L}$ of test solution and diluting with $50 \mu \mathrm{L}$ medium). Then, $50 \mu \mathrm{L}$ of exponentially growing cells at $2 \times 10^{5}$ promastigotes $/ \mathrm{mL}$ were added to each well to give final concentrations ranging from 12.5 to $200 \mu \mathrm{g} / \mathrm{mL}$. After an incubation of 72 hours at $26{ }^{\circ} \mathrm{C}, 20 \mu \mathrm{L}$ of 3-[4,5-dimethylthiazol-2-yl]-2,5-diphenyltetrazolium bromide (MTT) (SIGMA, St. Louis, MO, USA) was added. MTT solutions were prepared at $5 \mathrm{mg} / \mathrm{mL}$ in PBS, filtered and sterilized just prior to use. After incubation for an additional $4 \mathrm{~h}$, the formazan crystals were dissolved by addition of $100 \mu \mathrm{L}$ of DMSO. The optical density was determined using a spectrophotometer (Sirio S Reader, 2.4-0, Italy), at a test wavelength of $560 \mathrm{~nm}$ and a reference wavelength of $630 \mathrm{~nm}[23,24]$ and median inhibitory concentrations $\left(I C_{50}\right)$ were calculated.

\subsection{Cytotoxicity Assay}

The cytotoxic median concentration $\left(C C_{50}\right)$ of the extracts was determined on mouse peritoneal macrophages, which are the host cells for the amastigote form of the parasite, aiming to investigate macrophage toxicity caused by the extracts [23]. Resident macrophages were collected from peritoneal cavities of normal BALB/c mice in ice-cold RPMI 1640 medium (SIGMA, St. Louis, MO, USA) supplemented with antibiotics, and seeded at 30,000 cells/well. The cells were incubated for $2 \mathrm{~h}$ at $37{ }^{\circ} \mathrm{C}$ in $5 \% \mathrm{CO}_{2}$. Non-adherent cells were removed by washing with phosphate-buffered saline (PBS), and then $2 \mu \mathrm{L}$ of extract/DMSO solutions were added to $98 \mu \mathrm{L}$ medium with $10 \% \mathrm{HFBS}$ and antibiotics. Then, five two-fold dilutions were carried out taking $50 \mu \mathrm{L}$ each time and adding an additional $50 \mu \mathrm{L}$ of medium to give test concentrations of the extracts ranging from 12.5 to 200 $\mu \mathrm{g} / \mathrm{mL}$. The cells were incubated with the test solutions for $72 \mathrm{~h}$. Macrophages treated with DMSO were included as controls. The cytotoxicity was determined using the colorimetric assay with MTT as previously described; $15 \mu \mathrm{L}$ MTT solution added to each well. After incubation for an additional $4 \mathrm{~h}$ the formazan crystals were dissolved by addition of $100 \mu \mathrm{L}$ of DMSO and the optical density was determined.

\subsection{Selectivity Index}

The selectivity index (SI) ratio $\left(C C_{50}\right.$ for macrophage / I $C_{50}$ for promastigotes) was used to compare the toxicity of the extracts for murine macrophages and the activity against Leishmania promastigotes. Extracts with a SI $\geq 5$ or with $I C_{50}<12.5 \mu \mathrm{g} / \mathrm{mL}$ against promastigotes were selected for further anti-amastigote determination.

\subsection{Anti-Amastigote Assay}

The peritoneal macrophages were harvested and plated at $10^{6}$ cells $/ \mathrm{mL}$ in $24-$ well Lab-Tek plates $\left(\right.$ Costar $^{\circledR}$, Washington, DC, USA) and incubated at $37{ }^{\circ} \mathrm{C}$ under an atmosphere of $5 \% \mathrm{CO}_{2}$ for $2 \mathrm{~h}$. Non-adherent cells were removed by washing with PBS. Stationary-phase of L. amazonensis promastigotes were added at a 4:1 parasite/macrophage ratio and the cultures were incubated for an additional $4 \mathrm{~h}$. The cell monolayers were washed three times with PBS to remove free parasites. Then, $1990 \mu \mathrm{L}$ of RPMI completed medium and $10 \mu \mathrm{L}$ of the different extracts dissolved in DMSO were added to each well. Four two-fold dilutions were carried out taking $1000 \mu \mathrm{L}$ each time to give test 
concentrations of the extracts ranging from 12.5 to $100 \mu \mathrm{g} / \mathrm{mL}$, in duplicate cultures, incubating for an

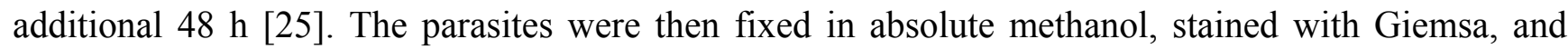
examined under light microscopy. The number of intracellular amastigotes was determined by counting the amastigotes in 25 macrophages per sample, and the results were expressed as percent of reduction of the infection rate in comparison to that of the controls. The infection rates were obtained by multiplying the percentage of infected macrophages by the number of amastigotes per infected macrophages [26] and the $I C_{50}$ value was determined. A second SI was calculated: $C C_{50}$ for macrophages $/ I C_{50}$ for intracellular amastigotes (see Table 1).

\subsection{Statistical Analyses}

The $I C_{50}$ of the tested extracts and reference drugs against $L$. amazonensis promastigotes and amastigotes and the $C C_{50}$ on peritoneal macrophages from BALB/c mice were obtained from dose-response curves fit to the data by means of the linear equation model using the STATISTICA for Windows Program (Release 4.5, StatSoft, Inc., Tulsa, OK, USA, 1993). The evaluations were performed in triplicate and the results are expressed as means \pm standard deviations.

\section{Results and Discussion}

A total of 115 different plant extracts from our collection, representing 96 plant species, have been screened for in vitro antileishmanial activity against $L$. amazonensis. In addition, the extracts were screened for cytotoxic activity against BALB/c mouse macrophages in order to assess a selectivity index. The antileishmanial and cytotoxic activities are summarized in Table 1. A total of 18 extracts showed activity against $L$. amazonensis promastigotes with $I C_{50}$ values $<12.5 \mu \mathrm{g} / \mathrm{mL}$. An additional 25 extracts showed antileishmanial activities ranging from $I C_{50} 17.4 \mu \mathrm{g} / \mathrm{mL}$ to $63.4 \mu \mathrm{g} / \mathrm{mL}$. Of the plant extracts that were active against $L$. amazonensis promastigotes, 18 were non-toxic to BALB/c mouse macrophages $\left(C C_{50}>200 \mu \mathrm{g} / \mathrm{mL}\right)$. In addition, 10 others were only slightly toxic to the mouse macrophages, showing selectivity indices $\left(C C_{50}\right.$ for macrophage $/ I C_{50}$ for promastigotes $) \geq 5$, and were considered for further testing against $L$. amazonensis amastigotes. Additional screening against L. amazonensis amastigotes revealed ten extracts with $I C_{50} \leq 21.0 \mu \mathrm{g} / \mathrm{mL}$ against the parasites and non-toxic to the mouse macrophages $\left(C C_{50}>200 \mu \mathrm{g} / \mathrm{mL}\right)$. That is, the selectivity indices $\left(C C_{50}\right.$ for macrophage $/ I C_{50}$ for amastigotes) for these extracts were all $>10$. It is generally considered that for plant extracts showing SI $>10$, the antiprotozoal activity is not due to general cytotoxicity and are promising extracts for further phytochemical analysis [27-29].

The methanol bark extract of Conostegia xalapensis (Melastomataceae) showed good leishmanicidal activity $\left(I C_{50}<12.5 \mu \mathrm{g} / \mathrm{mL}\right.$ against both promastigotes and amastigotes), but was neither cytotoxic to BALB/c mouse macrophages nor human tumor cells [21]. Thus, this plant extract shows excellent selectivity and apparently low acute toxicity. To our knowledge, no phytochemical work has been carried out on this plant; it is not known what compounds may be responsible for the antileishmanial activity. Although the dichloromethane bark extract of Quercus insignis (Fagaceae) was inactive, the ethanol bark extract exhibited notable antileishmanial activity against $L$. amazonensis promastigotes and amastigotes ( $I C_{50}=17.8$ and $21.0 \mu \mathrm{g} / \mathrm{mL}$, respectively). $Q$. insignis ethanol bark extract showed no in vitro 
toxicity to mouse macrophage cells or human tumor cells [21]. The phytochemistry of this tree has not been examined.

Interestingly, both the chloroform and methanol bark extracts of Exothea paniculata (Sapindaceae) from Monteverde, Costa Rica, showed good activity against L. amazonensis with little cytotoxicity on BALB/c mouse macrophages, but neither the acetone bark extract nor the methanol bark extract of E. paniculata from Abaco Island, Bahamas was leishmanicidal. The chloroform extract of E. paniculata from Monteverde showed the most promise with $I C_{50}<12.5 \mu \mathrm{g} / \mathrm{mL}$ against both the promastigote and amastigote forms of L. amazonensis, but non-toxic to macrophage cells. There have been no reported studies on the phytochemical composition of $E$. paniculata.

An ethanol extract of the aerial parts of Matelea pseudobarbata (Apocynaceae) was shown to be non-cytotoxic to mouse macrophages, but notably leishmanicidal against L. amazonensis promastigotes and amastigotes $\left(I C_{50}<12.5 \mu \mathrm{g} / \mathrm{mL}\right)$. Additionally, this extract was non-cytotoxic to Hep-G2, MCF-7, MDA-MB-231, and PC-3 tumor cell lines [21]. Apparently little else is known about this vine. The acetone bark extract of Stemmadenia donnell-smithii (Apocynaceae) was also antileishmanial $\left(I C_{50}<12.5 \mu \mathrm{g} / \mathrm{mL}\right)$ and non-toxic to the mouse macrophage. S. donnell-smithii is cytotoxic to human tumor cells, however [21]. A decoction of $S$. donnell-smithii bark is used as a traditional medicine in Guatemala to treat malaria [30]. Several indole alkaloids have been isolated from S. donnell-smithii, including $(+)$-quebrachamine, voacangine, isovoacangine, voacamine, tabernanthine, ibogamine, and stemmadine [31] and may be responsible for the leishmanicidal activity of S. donnell-smithii. An extract of Tabernaemontana catharinensis, rich in voacangine (53\%) has shown antileishmanial activity against L. amazonensis [32]. Voacamine has shown antiplasmodial activity [33] and a molecular docking study revealed voacamine to dock strongly to Leishmania $N$-myristoyl transferase as a molecular target [34].

Two different species of Eugenia (Myrtaceae) from Monteverde, Costa Rica, showed good antileishmanial activity. Thus, the acetone bark extracts of E. monteverdensis and Eugenia sp. "fine leaf" were active against $L$. amazonensis promastigotes $\left(I C_{50}=23.9\right.$ and $<12.5 \mu \mathrm{g} / \mathrm{mL}$, respectively), while neither was cytotoxic to BALB/c mouse macrophages $\left(C C_{50}>200 \mu \mathrm{g} / \mathrm{mL}\right)$. Furthermore, E. monteverdensis acetone bark extract was inactive against MCF-7 and Hs 578T human breast tumor cells (unpublished results from this laboratory), and Eugenia "fine leaf" acetone bark extracts was inactive on several human tumor cell lines (Hep-G2 MDA-MB-231, Hs 578T, and 5637) [21]. Consistent with these results, the ethanol bark extracts of E. austin-smithii and a Eugenia sp. from the Alberto Manuel Brenes Biological Reserve, Costa Rica, showed antileishmanial activity [35]. The acetone bark extract of E. austin-smithii has been found to be cytotoxic to Hs 578T, 5637, and BHK cells [21]. Both the hexane and methanol fruit extracts of E. umbelliflora were leishmanicidal to L. amazonensis and L. braziliensis promastigotes [36]. E. uniflora has been screened for antileishmanial activity. The ethanol leaf extract was marginally active against L. braziliensis promastigotes $(65 \%$ inhibition at $100 \mu \mathrm{g} / \mathrm{mL})$ [37], but inactive against L. amazonensis or L. chagasi promastigotes [38]. The leaf essential oil of E. uniflora showed good antileishmanial activity against both promastigotes and amastigotes of L. amazonensis $\left(I C_{50}=3.04\right.$ and $1.92 \mu \mathrm{g} / \mathrm{mL}$, respectively) [39], but $E$. uniflora bark essential oil was inactive against $L$. donovani promastigotes [40].

The bark of Endiandra palmerstonii (Lauraceae) from far north Queensland was extracted using a chloroform/ethanol mixed solvent [22]. The crude extract showed promising antileishmanial activity 
$\left(I C_{50}<12.5 \mu \mathrm{g} / \mathrm{mL}\right.$ on promastigotes and $18.7 \mu \mathrm{g} / \mathrm{mL}$ on amastigotes) and no cytotoxicity on BALB/c mouse macrophages $\left(C C_{50}>200 \mu \mathrm{g} / \mathrm{mL}\right)$. The extract was also non-cytotoxic to Hep-G2 human liver tumor cells [22]. There have been no phytochemical investigations reported for this tree species.

Two different bark extracts of Mallotus (Euphorbiaceae) from far north Queensland, Australia, M. mollisimus $\left(\mathrm{CHCl}_{3} /\right.$ EtOH mixed solvent bark extract) and M. paniculatus (EtOH bark extract), showed promising antileishmanial activity coupled with selectivity. M. paniculatus ethanol bark extract was the more promising with $I C_{50}<12.5 \mu \mathrm{g} / \mathrm{mL}$ on both promastigotes and amastigotes, and no cytotoxicity to macrophage cells. Previous screening for cytotoxicity against a panel of human tumor cell lines revealed M. paniculatus ethanol bark extract to be non-cytotoxic to Hep-G2, MDA-MB-231, Hs 578T, and 5673 cells [22]. Thus, this plant extract is apparently non-toxic to mammalian cells while remarkably toxic to the parasite. The triterpenoid 29-nor-3,22-hopanedione has been isolated from the stem bark of $M$. paniculatus, but no bioactivities were reported for this compound [41]. M. oppositifolius leaves are used in traditional medicine in the Ivory Coast to treat intestinal helminths, but the leaf extracts were inactive against $L$. donovani promastigotes [42].

Both the dichloromethane bark extract and the ethyl acetate bark extract of Sassafras albidum (Lauraceae), collected from north Alabama, showed notable antileishmanial activities against promastigotes $\left(I C_{50}<12.5\right.$ and $19.4 \mu \mathrm{g} / \mathrm{mL}$, respectively), and the dichloromethane extract had a median inhibitory concentration of $20.5 \mu \mathrm{g} / \mathrm{mL}$ against amastigotes of L. amazonensis. In addition, the extracts were non-toxic to macrophage cells. Although the essential oil compositions of $S$. albidum have been investigated $[43,44]$, apparently the non-volatile bark components have not. $S$. albidum bark oil is rich in $\alpha$-pinene, $\beta$-pinene, 1,8 -cineole, and $\alpha$-terpineol [44]. Many essential oils and components have shown antiprotozoal activities [45], including $\alpha$-pinene [46] and $\alpha$-terpineol [47].

The acetone bark extract of Acacia choriophylla (Fabaceae) from Abaco Island, Bahamas, showed a selectivity index $>3$. The dichloromethane bark extract of the same tree showed similar activity. Both of these crude extracts had been previously screened for in vitro cytotoxic activity against 5637 bladder tumor and $\mathrm{Hs} 578 \mathrm{~T}$ breast tumor cells (unpublished results from our laboratory) and were non-cytotoxic, so neither seems to be acutely toxic to human cells. The phytochemistry of this tree has not been examined.

The acetone bark extract of Tabebuia bahamensis (Bignoniaceae) was active against L. amazonensis promastigotes and amastigotes with $I C_{50}$ values of 17.4 and $23.8 \mu \mathrm{g} / \mathrm{mL}$, respectively. This bark extract was screened for cytotoxic activity against a panel of human tumor cell lines, including SK-Mel-38 (melanoma), Hep-G2 (hepatocellular carcinoma), MDA-MB-231 (mammary adenocarcinoma), and 5637 (bladder carcinoma), and was found to be inactive against all cell lines screened (unpublished results from our laboratory). T. umbellata is used traditionally in Bahia, Brazil to treat cutaneous leishmaniasis (L. braziliensis) infections [48]. Likewise, T. serratifolia bark is used in Peru to treat leishmaniasis, and T. serratifolia chloroform bark extract did show in vitro activity against L. infantum promastigotes [49]. Naphthoquinones from T. avellanedae [50] and T. serratifolia [49] have shown antileishmanial activity against L. major and L. infantum, respectively. Thus, the antileishmanial activity of T. bahamensis bark extract may also be due to naphthoquinones.

The bark resin from Agathis atropurpurea (Araucariaceae) exhibited good antileishmanial activity $\left(I C_{50}<12.5\right.$ and $19.3 \mu \mathrm{g} / \mathrm{mL}$, respectively against L. amazonensis promastigotes and amastigotes) along with weak cytotoxic activity against BALB/c mouse macrophage cells. This resin had shown 
cytotoxic activity against SK-MEL-28 human melanoma cells, but was inactive against the Hep-G2, MDA-MB-231, Hs 578T, MCF-7, and PC-3 cell lines [22]. The resin is rich in diterpenoids, including agatholic acid [51].

Four species of Melicope (Rutaceae) from north Queensland, Australia, were screened for antileishmanial activity. M. broadbentiana and $M$. vitiflora bark extracts were inactive, but $M$. jonesii chloroform bark extract and M. rubra ethanol bark extract showed promising activity against L. amazonensis promastigotes. Further screening revealed no selectivity for L. amazonensis amastigotes over mouse macrophages, however. Both M. jonesii and M. rubra bark extracts showed in vitro cytotoxicity to human tumor cells [22]. Although the leaf essential oils of $M$. jonesii and M. rubra have been investigated [52], there are no reports on the bark phytochemistry. The chloroform bark extract of Polyosma alangiacea (Escalloniaceae) from far north Queensland, Australia was somewhat leishmanicidal $\left(I C_{50}=60.9 \mu \mathrm{g} / \mathrm{mL}\right.$ ) against promastigotes, but non-cytotoxic to mammalian cells, either mouse macrophages or human tumor cells [22]. The phytochemistry of $P$. alangiacea bark has not been reported.

The chloroform bark extract of an, as yet, undescribed species of Myrcianthes "black fruit" (Myrtaceae) from Monteverde, Costa Rica, does show promise with leishmanicidal $I C_{50}$ of $<12.5$ and $18.3 \mu \mathrm{g} / \mathrm{mL}$, respectively, against promastigotes and amastigotes of L. amazonensis. The aerial parts of the liana Ruyschia phylladenia (Marcgraviaceae), collected from Monteverde, Costa Rica, were extracted with dichloromethane. The extract inhibited L. amazonensis promastigotes $\left(I C_{50}<12.5 \mu \mathrm{g} / \mathrm{mL}\right)$ and amastigotes $\left(I C_{50}=22.0 \mu \mathrm{g} / \mathrm{mL}\right)$. Although this extract was cytotoxic to human tumor cells [21] no cytotoxicity on BALB/c mouse macrophages was observed.

The dichloromethane bark extract of Cupania glabra (Sapindaceae), collected from Monteverde, Costa Rica, had shown remarkable in vitro cytotoxic activity against several human tumor cell lines, which was attributed to the fatty alcohol glycoside cupanioside [53]. The ethanol bark extract of this tree, on the other hand, was devoid of cytotoxic activity [21], and in this work, the ethanol extract was leishmanicidal $\left(I C_{50}=17.6\right.$ and $27.0 \mu \mathrm{g} / \mathrm{mL}$ on promastigotes and amastigotes, respectively $)$ and non-toxic to BALB/c mouse macrophages. Consistent with these results, the crude methanol bark extract of $C$. dentata from the Yucatan peninsula of Mexico showed in vitro antileishmanial activity against $L$. mexicana promastigotes $\left(I C_{50}=13 \mu \mathrm{g} / \mathrm{mL}\right)$ [54]. Interestingly, the crude hexane bark extract of $C$. cinerea showed in vitro leishmanicidal activity against L. donovani axenic amastigotes [29], possibly attributable to the diterpene glycoside cupacinoside [55]. Similarly, the hexane leaf extract of $C$. vernalis was active against $L$. donovani promastigotes [56]. Extracts of C. macrophylla from Costa Rica, on the other hand, were inactive against Leishmania promastigotes [35].

The crude ethanol bark extract of Diospyros digyna (Ebenaceae) showed in vitro antileishmanial activity against $L$. amazonensis promastigotes and amastigotes with $I C_{50}=25.0$ and $29.2 \mu \mathrm{g} / \mathrm{mL}$, respectively. Additionally, D. digyna extract was not cytotoxic to either BALB/c mouse macrophages or MCF-7, UACC-257, MDA-MB-231, or M-14 human tumor cells (unpublished results from this laboratory). Diospyrin, a bis-naphthoquinone isolated from $D$. montana, has shown in vitro activity against $L$. donovani promastigotes [57] and L. major promastigotes [58]. This compound has been shown to be a topoisomerase I inhibitor of L. donovani [59] and initiates apoptosis in L. donovani [60]. Antileishmanial bis-naphthoquinones have also been isolated and characterized from $D$. assimilis 
chloroform root extract from India (in vitro assay against L. donovani axenic amastigotes) [61] and D. burmanica methanol wood extract from Myanmar (in-vitro assay against L. major promastigotes) [62].

The crude ethanol bark extract of Erythrina lanceolata (Fabaceae) showed promising antileishmanial activity $\left(I C_{50}<12.5 \mu \mathrm{g} / \mathrm{mL}\right.$ against promastigotes) without cytotoxic activity against $\mathrm{BALB} / \mathrm{c}$ mouse macrophages or a number of human tumor cell lines (Hep-G2, MDA-MB-231, MCF-7, Hs 578T, PC-3, SK-MEL-28), or baby hamster kidney (BHK) cells [21]. In contrast, the crude dichloromethane bark extract was not leishmanicidal but cytotoxic to all cells tested [21]. The hydroalcoholic extract of $E$. speciosa from Brazil was tested for antileishmanial activity against both $L$. amazonensis promastigotes and amastigotes, but was inactive [63]. Likewise, the methanol wood extract of E. suberosa from Myanmar was inactive against L. major promastigotes [64], and the ethanol bark extract of E. variegata from New Caledonia was inactive against L. donovani promastigotes [65].

The acetone bark extract of Inga sierrae (Fabaceae) from Monteverde, Costa Rica, showed leishmanicidal activity $\left(I C_{50}=25.7 \mu \mathrm{g} / \mathrm{mL}\right)$ with reduced cytotoxic activity $\left(C C_{50}=130.6 \mu \mathrm{g} / \mathrm{mL}\right)$. Several Inga species are used in traditional medicine to treat leishmaniasis. I. edulis leaves are used by the Kichwa in Ecuador [29] while I. edulis bark is used by the Wayãpi people of French Guiana [66] to treat leishmaniasis. The Chachi people of Ecuador also use I. oerstediana leaves and bark [29] and I. bourgoni bark is also used by the Wayãpi [66] to treat leishmaniasis.

The methanol bark extract from Pappea capensis (Sapindaceae) collected in Matabeleland, Zimbabwe, also showed promising antileishmanial activity $\left(I C_{50}<12.5 \mu \mathrm{g} / \mathrm{mL}\right)$. Rhynchosia resinosa (Fabaceae) methanol root extract, from Matabeleland, Zimbabwe, did not exhibit cytotoxic activity toward BALB/c mouse macrophages, but was active against $L$. amazonensis amastigotes with an $I C_{50}$ of $27.7 \mu \mathrm{g} / \mathrm{mL}$. The methanol bark extract of $R$. edulis from Monteverde, Costa Rica was shown to be inactive against L. amazonensis (this work), while the methanol extract of the whole plant of $R$. reniformis from Karak, Pakistan was also non-leishmanicidal [67].

Both the dichloromethane and ethanol extracts of the aerial parts of Conradina canescens (Lamiaceae) from north Florida showed promising antileishmanial activity. The dichloromethane extract did show some cytotoxicity on BALB/c mouse macrophages $\left(C C_{50}=63.7 \mu \mathrm{g} / \mathrm{mL}\right)$ as well as MCF-7 and MDA-MB-231 human breast tumor cells (unpublished results from our laboratory). The essential oil composition of $C$. canescens has been reported [68], but there have been no reports regarding the non-volatile components. The major components in the essential oil were 1,8-cineole, camphor, $\alpha$-pinene, $p$-cymene, cis-pinocamphone, myrtenal, myrtenol, verbenone, and myrtenyl acetate. 1,8-Cineole is inactive against Leishmania spp. [69] but $\alpha$-pinene is active [46]. Myrtenal, camphor, and verbenone have shown antitrypanosomal activity [70]. 
Table 1. Antileishmanial (Leishmanial amazonensis promastigotes) and cytotoxic screening of tropical rainforest plant extracts.

\begin{tabular}{|c|c|c|c|c|c|c|c|c|}
\hline Plant Name & Origin & Extract & Ref. $p$ & $\begin{array}{c}\text { L. amazonensis } \\
\text { promastigotes } I C_{50} \\
(\mu \mathrm{g} / \mathrm{mL})\end{array}$ & $\begin{array}{c}\text { BALB/c } \\
{ }_{0} \begin{array}{c}\text { Mouse macrophage } \\
C C_{50}(\mu \mathrm{g} / \mathrm{mL})\end{array} \\
\end{array}$ & $\mathrm{e}^{\begin{array}{c}\text { Selectivity Index } \\
\left(C C_{50} / I C_{50}\right)\end{array}}$ & $\begin{array}{c}\text { L. amazonensis } \\
\text { amastigotes } I C_{50} \\
(\mu \mathrm{g} / \mathrm{mL})\end{array}$ & $\begin{array}{l}\text { Selectivity Index } \\
\qquad\left(C C_{50} / I C_{50}\right)\end{array}$ \\
\hline $\begin{array}{l}\text { Acacia choriophylla } \\
\text { Benth. }\end{array}$ & $\mathrm{Abaco}^{\mathrm{a}}$ & acetone bark & $\mathrm{b}$ & $63.4 \pm 4.9$ & $>200$ & $>3$ & $61.5 \pm 4.6$ & $>3$ \\
\hline $\begin{array}{c}\text { Acacia choriophylla } \\
\text { Benth. }\end{array}$ & Abaco & $\mathrm{CH}_{2} \mathrm{Cl}_{2}$ bark & $\mathrm{b}$ & $74.1 \pm 2.4$ & $197.6 \pm 1.4$ & 3 & - & - \\
\hline $\begin{array}{l}\text { Acnistus arborescens } \\
\text { (L.) Schltdl. }\end{array}$ & Monteverde $^{c}$ & acetone bark & [21] & $>200$ & $36.8 \pm 3.4$ & - & - & - \\
\hline $\begin{array}{l}\text { Acronychia acronychioides } \\
\text { (F. Muell.) T. Hartley }\end{array}$ & Paluma $^{\mathrm{d}}$ & EtOH bark & [20] & $>200$ & $47.3 \pm 7.6$ & - & - & - \\
\hline $\begin{array}{c}\text { Agathis atropurpurea } \\
\text { B. Hyland }\end{array}$ & F. No. Qld. ${ }^{\mathrm{e}}$ & bark resin & [22] & $<12.5$ & $118.4 \pm 0.8$ & $>9$ & $19.3 \pm 2.5$ & 6 \\
\hline $\begin{array}{l}\text { Albizia adinocephala (Donn. Sm.) } \\
\text { Britton \& Rose ex Record }\end{array}$ & Monteverde & acetone bark & $\mathrm{b}$ & $>200$ & $>200$ & - & - & - \\
\hline $\begin{array}{c}\text { Alchornea latifolia } \\
\text { Sw. }\end{array}$ & Monteverde & EtOH bark & [21] & $>200$ & $>200$ & - & - & - \\
\hline $\begin{array}{l}\text { Alloxylon flammeum } \\
\text { P. Westpm \& Crisp }\end{array}$ & F. No. Qld. & $\begin{array}{c}\mathrm{CHCl}_{3} / \mathrm{EtOH} \\
\text { bark }\end{array}$ & {$[22]$} & $>200$ & $55.5 \pm 9.1$ & - & - & - \\
\hline $\begin{array}{l}\text { Alphitonia petriei } \\
\text { Braid \& C. White }\end{array}$ & Paluma & EtOH bark & [20] & $>200$ & $>200$ & - & - & - \\
\hline $\begin{array}{l}\text { Alzatea verticillata } \\
\text { Ruiz \& Pav. }\end{array}$ & Monteverde & EtOH bark & [21] & $>200$ & $>200$ & - & - & - \\
\hline $\begin{array}{l}\text { Apodytes brachystylis } \\
\text { F. Muell. }\end{array}$ & Paluma & EtOH bark & [20] & $<12.5$ & $<12.5$ & 1 & - & - \\
\hline $\begin{array}{l}\text { Archidendron vaillantii } \\
\text { (F. Muell.) F. Muell. }\end{array}$ & Paluma & EtOH bark & [20] & $92.0 \pm 8.1$ & $<12.5$ & 0 & - & - \\
\hline $\begin{array}{c}\text { Ardisia compressa } \\
\text { Kunth }\end{array}$ & Monteverde & EtOH bark & [21] & $>200$ & $146.2 \pm 6.3$ & - & - & - \\
\hline
\end{tabular}


Table 1. Cont.

\begin{tabular}{|c|c|c|c|c|c|c|c|c|}
\hline Plant Name & Origin & Extract & Ref. $p$ & $\begin{array}{c}\text { L. amazonensis } \\
\text { promastigotes } I C_{50} \\
(\mu \mathrm{g} / \mathrm{mL})\end{array}$ & $\begin{array}{c}\text { BALB/c } \\
\text { Mouse macrophage } \\
C C_{50}(\mu \mathrm{g} / \mathrm{mL}) \\
\end{array}$ & $\begin{array}{c}\text { Selectivity Index } \\
\left(C C_{50} / I C_{50}\right)\end{array}$ & $\begin{array}{c}\text { L. amazonensis } \\
\text { amastigotes } I C_{50} \\
(\mu \mathrm{g} / \mathrm{mL})\end{array}$ & $\begin{array}{l}\text { Selectivity Index } \\
\qquad\left(C C_{50} / I C_{50}\right)\end{array}$ \\
\hline $\begin{array}{l}\text { Ardisia palmana } \\
\text { Donn. Sm. }\end{array}$ & Monteverde & acetone bark & {$[21]$} & $143.7 \pm 11.1$ & $96.6 \pm 2.6$ & - & - & - \\
\hline $\begin{array}{c}\text { Ardisia revoluta } \\
\text { Kunth }\end{array}$ & Monteverde & acetone bark & {$[21]$} & $>200$ & $70.5 \pm 6.2$ & - & - & - \\
\hline $\begin{array}{l}\text { Ardisia revoluta } \\
\text { Kunth }\end{array}$ & Monteverde & $\mathrm{CH}_{2} \mathrm{Cl}_{2}$ bark & [21] & $44.0 \pm 2.9$ & $49.2 \pm 1.5$ & 1 & - & - \\
\hline $\begin{array}{l}\text { Ardisia solomonii } \\
\text { Lundell }\end{array}$ & Monteverde & $\mathrm{CH}_{2} \mathrm{Cl}_{2}$ bark & $\mathrm{b}$ & $>200$ & $26.3 \pm 2.3$ & - & - & - \\
\hline $\begin{array}{l}\text { Ardisia solomonii } \\
\text { Lundell }\end{array}$ & Monteverde & $\mathrm{CH}_{2} \mathrm{Cl}_{2}$ bark & $\mathrm{b}$ & $28.1 \pm 2.0$ & $<12.5$ & - & - & - \\
\hline $\begin{array}{l}\text { Balanops australiana } \\
\text { F. Muell. }\end{array}$ & Paluma & EtOH bark & [20] & $49.0 \pm 4.3$ & $<12.5$ & 0 & - & - \\
\hline $\begin{array}{l}\text { Beilschmiedia sp. } \\
\text { "choncho blanco" }\end{array}$ & Monteverde & EtOH bark & [21] & $>200$ & $>200$ & - & - & - \\
\hline $\begin{array}{c}\text { Bocconia frutescens } \\
\text { L. }\end{array}$ & Monteverde & $\mathrm{MeOH}$ bark & [21] & $>200$ & $168.0 \pm 4.5$ & - & - & - \\
\hline $\begin{array}{l}\text { Bravaisia integerrima } \\
\text { (Spreng.) Standley }\end{array}$ & Monteverde & $\mathrm{CHCl}_{3}$ bark & [21] & $76.6 \pm 0.5$ & $21.6 \pm 5.0$ & 0 & - & - \\
\hline $\begin{array}{c}\text { Bridelia mollis } \\
\text { Hutch. }\end{array}$ & Matabeleland $^{\mathrm{f}}$ & $\mathrm{MeOH}$ bark & $\mathrm{b}$ & $>200$ & $>200$ & - & - & - \\
\hline $\begin{array}{c}\text { Byrsonima crassifolia } \\
\text { (L.) Kunth }\end{array}$ & Monteverde & acetone bark & $\mathrm{b}$ & $>200$ & $66.2 \pm 0.8$ & - & - & - \\
\hline
\end{tabular}


Table 1. Cont.

\begin{tabular}{|c|c|c|c|c|c|c|c|c|}
\hline Plant Name & Origin & Extract & Ref. & $\begin{array}{c}\text { L. amazonensis } \\
\text { promastigotes } I C_{50} \\
(\mu \mathrm{g} / \mathrm{mL})\end{array}$ & $\begin{array}{c}\text { BALB/c } \\
\text { Mouse macrophage } \\
C C_{50}(\mu \mathrm{g} / \mathrm{mL}) \\
\end{array}$ & $\begin{array}{l}\text { Selectivity Index } \\
\left(C C_{50} / I C_{50}\right)\end{array}$ & $\begin{array}{c}L . \text { amazonensis } \\
\text { amastigotes } I C_{50} \\
(\mu \mathrm{g} / \mathrm{mL})\end{array}$ & $\begin{array}{l}\text { Selectivity Index } \\
\qquad\left(C C_{50} / I C_{50}\right)\end{array}$ \\
\hline $\begin{array}{l}\text { Cardwellia sublimis } \\
\text { F. Muell. }\end{array}$ & Paluma & EtOH bark & {$[20]$} & $>200$ & $>200$ & - & - & - \\
\hline $\begin{array}{l}\quad \text { Cavendishia bracteata } \\
\text { (Ruiz \& Pav. ex J. St.-Hil.) Hoerold }\end{array}$ & Monteverde & acetone bark & $\mathrm{b}$ & $38.4 \pm 6.9$ & $76.0 \pm 5.6$ & 2 & - & - \\
\hline $\begin{array}{c}\text { Cestrum megalophyllum } \\
\text { Dunal }\end{array}$ & Monteverde & EtOH bark & {$[21]$} & $>200$ & $28.6 \pm 1.1$ & - & - & - \\
\hline $\begin{array}{l}\text { Chionanthus panamensis } \\
\text { (Standl.) Stearn }\end{array}$ & Monteverde & acetone bark & {$[21]$} & $>200$ & $78.2 \pm 6.4$ & - & - & - \\
\hline $\begin{array}{l}\text { Conostegia xalapensis } \\
\text { (Bonpl.) D. Don }\end{array}$ & Monteverde & $\mathrm{MeOH}$ bark & {$[21]$} & $<12.5$ & $>200$ & $>16$ & $<12.5$ & $>16$ \\
\hline $\begin{array}{c}\text { Conradina canescens } \\
\text { A. Gray }\end{array}$ & Florida $^{\mathrm{g}}$ & $\begin{array}{c}\mathrm{CH}_{2} \mathrm{Cl}_{2} \text { aerial } \\
\text { parts }\end{array}$ & $\mathrm{b}$ & $<12.5$ & $63.7 \pm 5.0$ & $>5$ & $20.5 \pm 5.0$ & 3 \\
\hline $\begin{array}{c}\text { Conradina canescens } \\
\text { A. Gray }\end{array}$ & Florida & $\begin{array}{l}\text { EtOH aerial } \\
\text { parts }\end{array}$ & $\mathrm{b}$ & $33.6 \pm 5.9$ & $202.8 \pm 6.8$ & 6 & $30.6 \pm 3.9$ & 7 \\
\hline $\begin{array}{l}\text { Cryptocarya corrugata } \\
\text { C. White \& Francis }\end{array}$ & Paluma & EtOH bark & {$[20]$} & $>200$ & $88.7 \pm 5.3$ & - & - & - \\
\hline $\begin{array}{c}\text { Cryptocarya densiflora } \\
\text { Blume }\end{array}$ & Paluma & EtOH bark & {$[20]$} & $>200$ & $>200$ & - & - & - \\
\hline $\begin{array}{c}\text { Cupania glabra } \\
\text { Sw. }\end{array}$ & Monteverde & EtOH bark & {$[21]$} & $17.6 \pm 5.3$ & $>200$ & $>11$ & $27.0 \pm 4.5$ & $>7$ \\
\hline $\begin{array}{l}\text { Daphandra repandula } \\
\text { (F. Muell.) F. Muell. }\end{array}$ & F. No. Qld. & $\begin{array}{c}\mathrm{CHCl}_{3} / \mathrm{EtOH} \\
\text { bark }\end{array}$ & {$[22]$} & $>200$ & $<12.5$ & - & - & - \\
\hline $\begin{array}{l}\text { Dendropanax gonatopus } \\
\text { (Donn. Sm.) A.C. Sm. }\end{array}$ & Monteverde & $\mathrm{MeOH}$ leaf & {$[23]$} & $>200$ & $72.4 \pm 7.2$ & - & - & - \\
\hline
\end{tabular}


Table 1. Cont.

\begin{tabular}{|c|c|c|c|c|c|c|c|c|}
\hline Plant Name & Origin & Extract & Ref. I & $\begin{array}{c}\text { L. amazonensis } \\
\text { promastigotes } I C_{50} \\
(\mu \mathrm{g} / \mathrm{mL})\end{array}$ & $\begin{array}{c}\text { BALB/c } \\
\text { Mouse macrophage } \\
C C_{50}(\mu \mathrm{g} / \mathrm{mL}) \\
\end{array}$ & $\begin{array}{l}\text { Selectivity Index } \\
\left(C C_{50} / I C_{50}\right)\end{array}$ & $\begin{array}{c}\text { L. amazonensis } \\
\text { amastigotes } I C_{50} \\
(\mu \mathrm{g} / \mathrm{mL})\end{array}$ & $\begin{array}{l}\text { Selectivity Index } \\
\qquad\left(C C_{50} / I C_{50}\right)\end{array}$ \\
\hline $\begin{array}{l}\text { Diospyros digyna } \\
\text { Jacq. }\end{array}$ & Monteverde & EtOH bark & $\mathrm{b}$ & $25.0 \pm 2.9$ & $152.9 \pm 8.8$ & 6 & $29.2 \pm 1.2$ & 5 \\
\hline $\begin{array}{l}\text { Diospyrus sp. } \\
\text { "fluted trunk" }\end{array}$ & Monteverde & EtOH bark & $\mathrm{b}$ & $>200$ & $57.4 \pm 3.5$ & - & - & - \\
\hline $\begin{array}{l}\text { Drymonia conchocalyx } \\
\text { Hanst. }\end{array}$ & Monteverde & $\begin{array}{l}\text { EtOH aerial } \\
\text { parts }\end{array}$ & [21] & $>200$ & 111.1 & - & - & - \\
\hline $\begin{array}{c}\text { Drypetes lasiogyna } \\
\text { F. Muell. }\end{array}$ & Paluma & EtOH bark & [20] & $47.6 \pm 2.2$ & $125.8 \pm 8.2$ & 3 & - & - \\
\hline $\begin{array}{c}\text { Elaeodendron matabelicum } \\
\text { Loes. }\end{array}$ & Matabeleland & $\mathrm{MeOH}$ bark & $\mathrm{b}$ & $>200$ & $125.7 \pm 9.0$ & - & - & - \\
\hline $\begin{array}{l}\text { Endiandra palmerstonii } \\
\text { (F.M. Bailey) C.T. White \& Francis }\end{array}$ & F. No. Qld. & $\begin{array}{c}\mathrm{CHCl}_{3} / \mathrm{EtOH} \\
\text { bark }\end{array}$ & [22] & $<12.5$ & $>200$ & $>16$ & $18.7 \pm 3.7$ & $>11$ \\
\hline $\begin{array}{l}\text { Erythrina lanceolata } \\
\text { Standl. }\end{array}$ & Monteverde & $\mathrm{CH}_{2} \mathrm{Cl}_{2}$ bark & [21] & $>200$ & $6.9 \pm 1.2$ & - & - & - \\
\hline $\begin{array}{l}\text { Erythrina lanceolata } \\
\text { Standl. }\end{array}$ & Monteverde & EtOH bark & [21] & $<12.5$ & $129.5 \pm 3.4$ & $>10$ & $22.3 \pm 3.4$ & 6 \\
\hline $\begin{array}{c}\text { Eugenia monteverdensis } \\
\text { Barrie }\end{array}$ & Monteverde & acetone bark & $\mathrm{b}$ & $23.9 \pm 2.8$ & $>200$ & $>8$ & $20.7 \pm 4.5$ & $>10$ \\
\hline $\begin{array}{l}\text { Eugenia sp. } \\
\text { "fine leaf" }\end{array}$ & Monteverde & acetone bark & [21] & $<12.5$ & $>200$ & $>16$ & $<12.5$ & $>16$ \\
\hline $\begin{array}{l}\text { Euphorbia elata } \\
\text { Brandegee }\end{array}$ & Monteverde & $\mathrm{MeOH}$ bark & [21] & $>200$ & $48.3 \pm 3.6$ & - & - & - \\
\hline $\begin{array}{c}\text { Euphorbia elata } \\
\text { Brandegee }\end{array}$ & Monteverde & acetone bark & [21] & $>200$ & $21.6 \pm 2.2$ & - & - & - \\
\hline
\end{tabular}


Table 1. Cont.

\begin{tabular}{|c|c|c|c|c|c|c|c|c|}
\hline Plant Name & Origin & Extract & Ref. I & $\begin{array}{c}\text { L. amazonensis } \\
\text { promastigotes } I C_{50} \\
(\mu \mathrm{g} / \mathrm{mL})\end{array}$ & $\begin{array}{c}\text { BALB/c } \\
\text { Mouse macrophage } \\
C C_{50}(\mu \mathrm{g} / \mathrm{mL}) \\
\end{array}$ & $\begin{array}{l}\text { Selectivity Index } \\
\left(C C_{50} / I C_{50}\right)\end{array}$ & $\begin{array}{c}\text { L. amazonensis } \\
\text { amastigotes } I C_{50} \\
(\mu \mathrm{g} / \mathrm{mL})\end{array}$ & $\begin{array}{l}\text { Selectivity Index } \\
\qquad\left(C C_{50} / I C_{50}\right)\end{array}$ \\
\hline $\begin{array}{l}\text { Exothea paniculata } \\
\text { (Juss.) Radlk. }\end{array}$ & Abaco & acetone bark & $\mathrm{b}$ & $>200$ & $49.8 \pm 1.8$ & - & - & - \\
\hline $\begin{array}{l}\text { Exothea paniculata } \\
\text { (Juss.) Radlk. }\end{array}$ & Abaco & $\mathrm{MeOH}$ bark & $\mathrm{b}$ & $>200$ & $>200$ & - & - & - \\
\hline $\begin{array}{l}\text { Exothea paniculata } \\
\text { (Juss.) Radlk. }\end{array}$ & Monteverde & $\mathrm{CHCl}_{3}$ bark & $\mathrm{b}$ & $<12.5$ & $>200$ & $>16$ & $<12.5$ & $>16$ \\
\hline $\begin{array}{l}\text { Exothea paniculata } \\
\text { (Juss.) Radlk. }\end{array}$ & Monteverde & $\mathrm{MeOH}$ bark & $\mathrm{b}$ & $33.2 \pm 3.6$ & $159.1 \pm 7.5$ & 5 & $32.3 \pm 7.5$ & 5 \\
\hline $\begin{array}{c}\text { Forestiera carthaginense } \\
\text { Donn. Sm. }\end{array}$ & Monteverde & $\begin{array}{c}\mathrm{CHCl}_{3} / \mathrm{EtOH} \\
\text { bark }\end{array}$ & [21] & $>200$ & $>200$ & - & - & - \\
\hline $\begin{array}{c}\text { Inga sierrae } \\
\text { Britton \& Killip }\end{array}$ & Monteverde & acetone bark & [21] & $25.7 \pm 1.9$ & $130.6 \pm 2.5$ & 5 & $29.9 \pm 5.5$ & 4 \\
\hline $\begin{array}{c}\text { Lonchocarpus oliganthus } \\
\text { F.J. Herm }\end{array}$ & Monteverde & acetone bark & [21] & $20.6 \pm 2.6$ & $29.8 \pm 4.8$ & 1 & - & - \\
\hline $\begin{array}{c}\text { Lonchocarpus orotinus } \\
\text { Pittier }\end{array}$ & Monteverde & acetone bark & $\mathrm{b}$ & $>200$ & $176.8 \pm 5.9$ & - & - & - \\
\hline $\begin{array}{c}\text { Macaranga subdentata } \\
\text { Benth. }\end{array}$ & Paluma & $\begin{array}{c}\mathrm{CHCl}_{3} / \mathrm{EtOH} \\
\text { leaf }\end{array}$ & [20] & $>200$ & $>200$ & - & - & - \\
\hline $\begin{array}{c}\text { Machaerium biovulatum } \\
\text { Micheli }\end{array}$ & Monteverde & acetone bark & [21] & $>200$ & $120.8 \pm 4.5$ & - & - & - \\
\hline $\begin{array}{l}\text { Mallotus mollissimus } \\
\text { (Geiseler) Airy Shaw }\end{array}$ & F. No. Qld. & $\begin{array}{c}\mathrm{CHCl}_{3} / \mathrm{EtOH} \\
\text { bark }\end{array}$ & {$[22]$} & $20.9 \pm 0.3$ & $>200$ & $>10$ & $25.2 \pm 1.0$ & $>8$ \\
\hline $\begin{array}{l}\text { Mallotus paniculatus } \\
\text { (Lam.) Muell. Arg. }\end{array}$ & F. No. Qld. & EtOH bark & [22] & $<12.5$ & $>200$ & $>16$ & $<12.5$ & $>16$ \\
\hline
\end{tabular}


Table 1. Cont.

\begin{tabular}{|c|c|c|c|c|c|c|c|c|}
\hline Plant Name & Origin & Extract & Ref. & $\begin{array}{c}\text { L. amazonensis } \\
\text { promastigotes } I C_{50} \\
(\mu \mathrm{g} / \mathrm{mL})\end{array}$ & $\begin{array}{c}\text { BALB/c } \\
\text { Mouse macrophage } \\
C C_{50}(\mu \mathrm{g} / \mathrm{mL})\end{array}$ & $\begin{array}{l}\text { Selectivity Index } \\
\left(C C_{50} / I C_{50}\right)\end{array}$ & $\begin{array}{c}L . \text { amazonensis } \\
\text { amastigotes } I C_{50} \\
(\mu \mathrm{g} / \mathrm{mL})\end{array}$ & $\begin{array}{l}\text { Selectivity Index } \\
\qquad\left(C C_{50} / I C_{50}\right)\end{array}$ \\
\hline $\begin{array}{l}\text { Matelea pseudobarbata } \\
\text { (Pittier) Woodson }\end{array}$ & Monteverde & $\begin{array}{l}\text { EtOH aerial } \\
\text { parts }\end{array}$ & {$[21]$} & $<12.5$ & $>200$ & $>16$ & $<12.5$ & $>16$ \\
\hline $\begin{array}{c}\text { Melicope broadbentiana } \\
\text { Bailey }\end{array}$ & Paluma & $\begin{array}{c}\mathrm{CHCl}_{3} / \mathrm{EtOH} \\
\text { bark }\end{array}$ & {$[20]$} & $23.7 \pm 4.3$ & $79.7 \pm 0.3$ & 3 & - & - \\
\hline $\begin{array}{c}\text { Melicope jonesii } \\
\text { T.G. Hartley }\end{array}$ & F. No. Qld. & $\mathrm{CHCl}_{3}$ bark & {$[22]$} & $<12.5$ & $35.5 \pm 8.6$ & $>3$ & $33.4 \pm 5.0$ & 1 \\
\hline $\begin{array}{c}\text { Melicope rubra } \\
\text { (Lauterb. \& K. Schum) T.G. Hartley }\end{array}$ & F. No. Qld. & EtOH bark & {$[22]$} & $<12.5$ & $29.6 \pm 0.4$ & $>2$ & $22.0 \pm 2.0$ & 1 \\
\hline $\begin{array}{l}\text { Melicope vitiflora } \\
\text { (F. Muell.) T. Hartley }\end{array}$ & Paluma & EtOH bark & {$[20]$} & $>200$ & $62.6 \pm 3.6$ & - & - & - \\
\hline $\begin{array}{l}\text { Mucuna urens } \\
\text { (L.) DC. }\end{array}$ & Monteverde & $\mathrm{MeOH}$ bark & {$[21]$} & $>200$ & $63.6 \pm 4.2$ & - & - & - \\
\hline $\begin{array}{l}\text { Myrcianthes sp. } \\
\text { "black fruit" }\end{array}$ & Monteverde & $\mathrm{CHCl}_{3}$ bark & {$[21]$} & $<12.5$ & $48.8 \pm 2.0$ & $>4$ & $18.3 \pm 4.4$ & 3 \\
\hline $\begin{array}{l}\text { Neea psychotrioides } \\
\text { Donn. Sm. }\end{array}$ & Monteverde & $\mathrm{CHCl}_{3}$ bark & {$[21]$} & $>200$ & $>200$ & - & - & - \\
\hline $\begin{array}{l}\text { Neolitsea dealbata } \\
\text { (R. Br.) Merr. }\end{array}$ & Paluma & EtOH bark & {$[20]$} & $>200$ & $>200$ & - & - & - \\
\hline $\begin{array}{l}\text { Ocotea sp. } \\
\text { "los llanos" }\end{array}$ & Monteverde & acetone bark & $\mathrm{b}$ & $>200$ & $>200$ & - & - & - \\
\hline $\begin{array}{l}\text { Octea meziana } \\
\text { C.K. Allen }\end{array}$ & Monteverde & acetone bark & {$[21]$} & $>200$ & $132.1 \pm 6.8$ & - & - & - \\
\hline $\begin{array}{c}\text { Ormosia cruenta } \\
\text { Rudd }\end{array}$ & Monteverde & acetone bark & {$[21]$} & $>200$ & $198.5 \pm 2.1$ & - & - & - \\
\hline
\end{tabular}


Table 1. Cont.

\begin{tabular}{|c|c|c|c|c|c|c|c|c|}
\hline Plant Name & Origin & Extract & Ref. $\mathrm{F}$ & $\begin{array}{c}\text { L. amazonensis } \\
\text { promastigotes } I C_{50} \\
(\mu \mathrm{g} / \mathrm{mL})\end{array}$ & $\begin{array}{c}\text { BALB/c } \\
\text { Mouse macrophage } \\
C C_{50}(\mu \mathrm{g} / \mathrm{mL}) \\
\end{array}$ & $\begin{array}{c}\text { Selectivity Index } \\
\left(C C_{50} / I C_{50}\right)\end{array}$ & $\begin{array}{c}\text { L. amazonensis } \\
\text { amastigotes } I C_{50} \\
(\mu \mathrm{g} / \mathrm{mL})\end{array}$ & $\begin{array}{l}\text { Selectivity Index } \\
\quad\left(C C_{50} / I C_{50}\right)\end{array}$ \\
\hline $\begin{array}{l}\text { Pappea capensis } \\
\text { Eckl. \& Zeyh. }\end{array}$ & Matabeleland & $\mathrm{MeOH}$ bark & $\mathrm{b}$ & $<12.5$ & $55.6 \pm 7.4$ & $>4$ & $<12.5$ & $>4$ \\
\hline $\begin{array}{l}\text { Phoradendron cf. Flavens } \\
\qquad(\mathrm{Sw}) \text { Griseb. }\end{array}$ & Monteverde & $\begin{array}{c}\mathrm{CH}_{2} \mathrm{Cl}_{2} / \mathrm{EtOH} \\
\text { aerial parts }\end{array}$ & {$[21]$} & $>200$ & $>200$ & - & - & - \\
\hline $\begin{array}{c}\text { Phoradendron robustissimum } \\
\text { Eichler }\end{array}$ & Monteverde & $\begin{array}{c}\mathrm{CH}_{2} \mathrm{Cl}_{2} / \mathrm{EtOH} \\
\text { aerial parts }\end{array}$ & {$[21]$} & $44.1 \pm 4.9$ & 166.4 & 4 & - & - \\
\hline $\begin{array}{c}\text { Phoradendron robustissimum } \\
\text { Eichler }\end{array}$ & Monteverde & $\begin{array}{l}\mathrm{CH}_{2} \mathrm{Cl}_{2} / \mathrm{EtOH} \\
\text { flowers }\end{array}$ & {$[21]$} & $>200$ & $>200$ & - & - & - \\
\hline $\begin{array}{c}\text { Piper aequale } \\
\text { Vahl }\end{array}$ & Monteverde & acetone leaf & [21] & $81.1 \pm 1.4$ & $35.9 \pm 7.6$ & 0 & - & - \\
\hline $\begin{array}{c}\text { Polyosma alangiacea } \\
\text { F. muell. }\end{array}$ & F. No. Qld. & $\mathrm{CHCl}_{3}$ bark & [22] & $60.9 \pm 8.9$ & $>200$ & $>3$ & $46.2 \pm 3.7$ & $>4$ \\
\hline $\begin{array}{c}\text { Psychotria parvifolia } \\
\text { Benth. }\end{array}$ & Monteverde & acetone bark & $\mathrm{b}$ & $>200$ & $>200$ & - & - & - \\
\hline $\begin{array}{l}\text { Quercus insignis } \\
\text { M. Martens \& Galeotti }\end{array}$ & Monteverde & $\mathrm{CH}_{2} \mathrm{Cl}_{2}$ bark & [21] & $>200$ & $161.4 \pm 6.3$ & - & - & - \\
\hline $\begin{array}{c}\text { Quercus insignis } \\
\text { M. Martens \& Galeotti }\end{array}$ & Monteverde & EtOH bark & [21] & $17.8 \pm 2.3$ & $>200$ & $>11$ & $21.0 \pm 3.0$ & $>10$ \\
\hline $\begin{array}{l}\text { Rhynchosia edulis } \\
\text { Griseb. }\end{array}$ & Monteverde & $\mathrm{MeOH}$ bark & [21] & $>200$ & $144.9 \pm 1.2$ & - & - & - \\
\hline $\begin{array}{l}\text { Rhynchosia resinosa } \\
\text { Hochst. ex Baker }\end{array}$ & Matabeleland & $\mathrm{MeOH}$ root & $\mathrm{b}$ & $54.1 \pm 4.2$ & $>200$ & $>4$ & $27.7 \pm 5.4$ & $>7$ \\
\hline $\begin{array}{c}\text { Ruyschia phylladenia } \\
\text { Sandwith }\end{array}$ & Monteverde & $\begin{array}{c}\mathrm{CH}_{2} \mathrm{Cl}_{2} \text { aerial } \\
\text { parts }\end{array}$ & {$[21]$} & $<12.5$ & $>200$ & $>16$ & $22.0 \pm 5.9$ & $>9$ \\
\hline
\end{tabular}


Table 1. Cont.

\begin{tabular}{|c|c|c|c|c|c|c|c|c|}
\hline Plant Name & Origin & Extract & Ref. I & $\begin{array}{c}\text { L. amazonensis } \\
\text { promastigotes } I C_{50} \\
(\mu \mathrm{g} / \mathrm{mL})\end{array}$ & $\begin{array}{c}\text { BALB/c } \\
\text { Mouse macrophage } \\
C C_{50}(\mu \mathrm{g} / \mathrm{mL}) \\
\end{array}$ & $\begin{array}{l}\text { Selectivity Index } \\
\left(C C_{50} / I C_{50}\right)\end{array}$ & $\begin{array}{c}\text { L. amazonensis } \\
\text { amastigotes } I C_{50} \\
(\mu \mathrm{g} / \mathrm{mL})\end{array}$ & $\begin{array}{l}\text { Selectivity Index } \\
\qquad\left(C C_{50} / I C_{50}\right)\end{array}$ \\
\hline $\begin{array}{l}\text { Salacia petenesis } \\
\text { Lundell }\end{array}$ & Monteverde & EtOH bark & [21] & $>200$ & $35.4 \pm 0.8$ & - & - & - \\
\hline $\begin{array}{l}\text { Salacia sp. } \\
\text { "liana" }\end{array}$ & Monteverde & $\mathrm{CH}_{2} \mathrm{Cl}_{2}$ bark & [21] & $>200$ & $79.2 \pm 3.8$ & - & - & - \\
\hline $\begin{array}{l}\text { Salacia sp. } \\
\text { "liana" }\end{array}$ & Monteverde & $\mathrm{MeOH}$ bark & [21] & $>200$ & $91.5 \pm 0.3$ & - & - & - \\
\hline $\begin{array}{l}\text { Sapium glandulosum } \\
\text { (L.) Morong }\end{array}$ & Monteverde & acetone bark & [21] & $>200$ & $>200$ & - & - & - \\
\hline $\begin{array}{l}\text { Sapium glandulosum } \\
\text { (L.) Morong }\end{array}$ & Monteverde & $\mathrm{CH}_{2} \mathrm{Cl}_{2}$ bark & [21] & $>200$ & $73.3 \pm 5.6$ & - & - & - \\
\hline $\begin{array}{l}\text { Sapium glandulosum } \\
\text { (L.) Morong }\end{array}$ & Monteverde & EtOH bark & [21] & $>200$ & $>200$ & - & - & - \\
\hline $\begin{array}{l}\text { Sassafras albidum } \\
\text { (Nutt.) Nees }\end{array}$ & Alabama $^{\mathrm{h}}$ & $\mathrm{CH}_{2} \mathrm{Cl}_{2}$ bark & $\mathrm{b}$ & $<12.5$ & $>200$ & $>16$ & $20.5 \pm 0.6$ & $>10$ \\
\hline $\begin{array}{l}\text { Sassafras albidum } \\
\text { (Nutt.) Nees }\end{array}$ & Alabama & EtOAc bark & $\mathrm{b}$ & $19.4 \pm 3.8$ & $>200$ & $>10$ & & \\
\hline $\begin{array}{l}\text { Saurauia montana } \\
\text { Seem }\end{array}$ & Monteverde & acetone leaf & [21] & $>200$ & $>200$ & - & - & - \\
\hline $\begin{array}{l}\text { Sinclaria polyantha } \\
\text { (Klatt) Rydb. }\end{array}$ & Monteverde & $\begin{array}{c}\mathrm{CHCl}_{3} / \mathrm{EtOH} \\
\text { leaf }\end{array}$ & [21] & $>200$ & $>200$ & - & - & - \\
\hline $\begin{array}{c}\text { Sorocea trophoides } \\
\text { W.C. Burger }\end{array}$ & Monteverde & $\mathrm{MeOH}$ bark & [21] & $>200$ & $>200$ & - & - & - \\
\hline $\begin{array}{l}\text { Stauranthus perforatus } \\
\text { Leibm. }\end{array}$ & Monteverde & EtOH bark & [21] & $>200$ & $>200$ & - & - & - \\
\hline
\end{tabular}


Table 1. Cont.

\begin{tabular}{|c|c|c|c|c|c|c|c|c|}
\hline Plant Name & Origin & Extract & Ref. & $\begin{array}{c}\text { L. amazonensis } \\
\text { promastigotes } I C_{50} \\
(\mu \mathrm{g} / \mathrm{mL})\end{array}$ & $\begin{array}{c}\text { BALB/c } \\
\text { Mouse macrophage } \\
C C_{50}(\mu \mathrm{g} / \mathrm{mL})\end{array}$ & $\begin{array}{l}\text { Selectivity Index } \\
\qquad\left(C C_{50} / I C_{50}\right)\end{array}$ & $\begin{array}{c}\text { L. amazonensis } \\
\text { amastigotes } I C_{50} \\
(\mu \mathrm{g} / \mathrm{mL})\end{array}$ & $\begin{array}{l}\text { Selectivity Index } \\
\qquad\left(C C_{50} / I C_{50}\right)\end{array}$ \\
\hline $\begin{array}{l}\text { Stemmadenia donnell-smithii } \\
\text { (Rose) Woodson }\end{array}$ & Monteverde & acetone bark & {$[21]$} & $<12.5$ & $>200$ & $>16$ & $<12.5$ & $>16$ \\
\hline $\begin{array}{l}\text { Stenocarpus sinuatus } \\
\text { (Loudon) Endl. }\end{array}$ & F. No. Qld. & $\begin{array}{c}\mathrm{CHCl}_{3} / \mathrm{EtOH} \\
\text { bark }\end{array}$ & {$[22]$} & $39.0 \pm 1.0$ & $36.8 \pm 0.3$ & 1 & - & - \\
\hline $\begin{array}{c}\text { Stockwellia quadrifida } \\
\text {.J. Carr, S.G.M. Carr, \& B. Hyland }\end{array}$ & F. No. Qld. & EtOH bark & {$[22]$} & $>200$ & $>200$ & - & - & - \\
\hline $\begin{array}{l}\text { Struthanthus cf. oerstedii } \\
\text { (Oliv.) Standl. }\end{array}$ & Monteverde & $\begin{array}{c}\mathrm{CHCl}_{3} / \mathrm{EtOH} \\
\text { leaf }\end{array}$ & {$[21]$} & $>200$ & $>200$ & - & - & - \\
\hline $\begin{array}{c}\text { Styphnolobium monteviridis } \\
\text { M. Sousa \& Rudd }\end{array}$ & Monteverde & $\mathrm{MeOH}$ leaf & [21] & $>200$ & $194.8 \pm 7.3$ & - & - & - \\
\hline $\begin{array}{c}\text { Styphnolobium monteviridis } \\
\text { M. Sousa \& Rudd }\end{array}$ & Monteverde & $\mathrm{MeOH}$ bark & {$[21]$} & $>200$ & $105.3 \pm 7.4$ & - & - & - \\
\hline $\begin{array}{l}\text { Symplocos limoncillo } \\
\text { Humb. \& Bonpl. }\end{array}$ & Monteverde & EtOH bark & [21] & $>200$ & $>200$ & - & - & - \\
\hline $\begin{array}{l}\text { Syncarpia glomulifera } \\
\text { (Smith) Niedenzu }\end{array}$ & Paluma & $\mathrm{CHCl}_{3}$ bark & {$[20]$} & $>200$ & $>200$ & - & - & - \\
\hline $\begin{array}{l}\text { Syncarpia glomulifera } \\
\text { (Smith) Niedenzu }\end{array}$ & Paluma & EtOH bark & {$[20]$} & $>200$ & $>200$ & - & - & - \\
\hline $\begin{array}{l}\text { Syzygium gustavioides } \\
\text { (F.M. Bailey) B. Hyland }\end{array}$ & F. No. Qld. & $\begin{array}{c}\mathrm{CHCl}_{3} / \mathrm{EtOH} \\
\text { bark }\end{array}$ & {$[22]$} & $>200$ & $>200$ & - & - & - \\
\hline $\begin{array}{l}\text { Tabebuia bahamensis } \\
\text { (Northr.) Britton }\end{array}$ & Abaco & acetone bark & $\mathrm{b}$ & $17.4 \pm 3.5$ & $>200$ & $>11$ & $23.8 \pm 5.7$ & $>8$ \\
\hline $\begin{array}{l}\text { Weinmannia pinnata } \\
\text { L. }\end{array}$ & Monteverde & EtOH bark & {$[21]$} & $>200$ & $>200$ & - & - & - \\
\hline
\end{tabular}


Table 1. Cont.

\begin{tabular}{|c|c|c|c|c|c|c|c|c|}
\hline Plant Name & Origin & Extract & Ref. I & $\begin{array}{c}\text { L. amazonensis } \\
\text { promastigotes } I C_{50} \\
(\mu \mathrm{g} / \mathrm{mL})\end{array}$ & $\begin{array}{c}\text { BALB/c } \\
\text { Mouse macrophage } \\
C C_{50}(\mu \mathrm{g} / \mathrm{mL}) \\
\end{array}$ & $\begin{array}{c}\text { Selectivity Index } \\
\left(C C_{50} / I C_{50}\right)\end{array}$ & $\begin{array}{c}\text { L. amazonensis } \\
\text { amastigotes } I C_{50} \\
(\mu \mathrm{g} / \mathrm{mL}) \\
\end{array}$ & $\begin{array}{l}\text { Selectivity Index } \\
\qquad\left(C C_{50} / I C_{50}\right)\end{array}$ \\
\hline $\begin{array}{l}\text { Xanthophyllum octandrum } \\
\text { (F. Muell.) Domin }\end{array}$ & Paluma & EtOH bark & [20] & $33.7 \pm 3.6$ & $20.6 \pm 0.6$ & 1 & - & - \\
\hline $\begin{array}{l}\text { Zanthoxylum rhoifolium } \\
\text { Lam. }\end{array}$ & Monteverde & $\mathrm{MeOH}$ bark & $\mathrm{b}$ & $34.2 \pm 2.3$ & $122.0 \pm 7.0$ & 4 & - & - \\
\hline $\begin{array}{l}\text { Zanthoxylum setulosum } \\
\text { P. Wilson }\end{array}$ & Monteverde & $\mathrm{MeOH}$ bark & [21] & $188.9 \pm 1.6$ & $>200$ & - & - & - \\
\hline $\begin{array}{l}\text { Zanthoxylum setulosum } \\
\text { P. Wilson }\end{array}$ & Monteverde & $\mathrm{MeOH}$ bark & [21] & $>200$ & $>200$ & - & - & - \\
\hline $\begin{array}{c}\text { Zanthoxylum setulosum } \\
\text { P. Wilson }\end{array}$ & Monteverde & $\mathrm{CHCl}_{3}$ bark & [21] & $>200$ & $>200$ & - & - & - \\
\hline $\begin{array}{l}\text { Zanthoxylum sp. aff. Juniperinum } \\
\text { Poepp }\end{array}$ & Monteverde & EtOH bark & [21] & $<12.5$ & $14.9 \pm 2.2$ & $>1$ & - & - \\
\hline $\begin{array}{l}\text { Zanthoxylum veneficum } \\
\text { F.M. Bailey }\end{array}$ & F. No. Qld. & $\begin{array}{c}\mathrm{CHCl}_{3} / \mathrm{EtOH} \\
\text { bark }\end{array}$ & [22] & $>200$ & $66.6 \pm 7.9$ & - & - & - \\
\hline Amphotericin B & - & - & - & $0.030 \pm 0.003$ & $5.8 \pm 0.5$ & 193 & $0.030 \pm 0.003$ & 193 \\
\hline Pentamidine & - & - & - & $0.37 \pm 0.01$ & $11.7 \pm 1.7$ & 32 & $1.3 \pm 0.1$ & 9 \\
\hline
\end{tabular}

${ }^{a}$ Abaco Island, Bahamas. ${ }^{\mathrm{b}}$ Unpublished. ${ }^{\mathrm{c}}$ Monteverde, Costa Rica. ${ }^{\mathrm{d}}$ Paluma, north Queensland, Australia. ${ }^{\mathrm{e}}$ Far north Queensland, Australia. ${ }^{\mathrm{f}}$ Matabeleland, Zimbabwe. ${ }^{\mathrm{g}}$ Navarre, Florida, USA.

${ }^{\mathrm{h}}$ Huntsville, Alabama, USA. 


\section{Conclusions}

Of the 115 extracts screened, 25 (21.7\%) showed promising activity against L. amazonensis promastigotes with low cytotoxic activity. Additional antileishmanial screening against $L$. amazonensis amastigotes revealed ten of these extracts $(8.7 \%)$ to be considered "hits", with selectivity indices, $C C_{50}$ (macrophage) $/ I C_{50}$ (amastigotes) greater than 10 that are worthy candidates for further phytochemical exploration: Conostegia xalapensis methanol bark extract, Endiandra palmerstonii bark extract, Eugenia monteverdensis acetone bark extract, Eugenia sp. "fine leaf" acetone bark extract, Exothea paniculata chloroform bark extract, Mallotus paniculatus ethanol bark extract, Matelea pseudobarbata ethanol extract, Quercus insignis ethanol bark extract, Sassafras albidum dichloromethane bark extract, and Stemmadenia donnell-smithii acetone bark extract. The good antileishmanial activity coupled with low cytotoxicity to mammalian cells indicates promise in terms of therapeutic index. Phytochemical analyses are currently underway in our laboratories. The results of this study demonstrate the medicinal potential of tropical rainforests and may provide complementary, safe, and affordable therapeutics for treatment of leishmaniasis. A total of 85 extracts were inactive or unspecific, which constitute $74 \%$ of tested samples, and reinforces the need to screen large series of natural products to find promising ones.

\section{Acknowledgments}

We thank Forest Heights Academy, Marsh Harbour, for allowing us the use of their laboratory facilities on Abaco. We are grateful to the Queensland Forest Service and to the Queensland National Parks and Wildlife Service for allowing access to State Forest and National Park lands. We thank Betsy R. Jackes and Anthony K. Irvine for plant identification in north Queensland, Australia. We are very grateful to the Monteverde Cloud Forest Preserve and the Tropical Science Center for granting us permission to collect plant materials under a cooperative rights agreement and to the Commission for the Development of Biodiversity of Costa Rica's Ministry of the Environment, Energy, and Telecommunications for Research Permit R-001-2006-OT-CONAGEBIO. We are grateful to Maynor Vargas Arguedas for permission to collect plant materials on the property of Hotel El Bosque, Monteverde. We thank William A. Haber and Robert O. Lawton for plant identification in Monteverde, Costa Rica. Financial support for the collection and extraction of plant materials was provided, in part, by grants from the National Institutes of Health (R15-AIOD39740-01, R15-GM46120-01A1，R15-CA74343-01，R15-GM57646-01A， R15-AI059001-01) and private donations. This work was performed as part of the activities of the Research Network Natural Products against Neglected Diseases (ResNetNPND), (http://www.resnetnpnd.org/Start/).

\section{Author Contributions}

L.M. and W.N.S. conceived and designed the project; L.M. and A.P. performed the experiments; L.M. and W.N.S. analyzed the data; W.N.S. wrote the manuscript.

\section{Conflicts of Interest}

The authors declare no conflict of interest. 


\section{References}

1. Alvar, J.; Vélez, I.D.; Bern, C.; Herrero, M.; Desjeux, P.; Cano, J.; Jannin, J.; den Boer, M.; the WHO Leishmaniasis Control Team. Leishmaniasis worldwide and global estimates of its incidence. PLoS One 2012, 7, doi:10.1371/journal.pone.0035671.

2. Stockdale, L.; Newton, R. A review of preventative methods against human leishmaniasis infection. PLoS Negl. Trop. Dis. 2013, 7, doi:10.1371/journal.pntd.0002278.

3. González, C.; Wang, O.; Strutz, S.E.; González-Salazar, C.; Sánchez-Cordero, V.; Sarkar, S. Climate change and risk of leishmaniasis in North America: Predictions from ecological niche models of vector and reservoir species. PLoS Negl. Trop. Dis. 2010, 4, doi:10.1371/journal.pntd.0000585.

4. Aspöck, H.; Gerersdorfer, T.; Formayer, H.; Walochnik, J. Sandflies and sandfly-borne infections of humans in Central Europe in the light of climate change. Wien. Klin. Wochenschr. 2008, 120, 24-29.

5. Semenza, J.C.; Menne, B. Climate change and infectious diseases in Europe. Lancet Infect. Dis. 2009, 9, 365-375.

6. Minter, L.; Kovacic, B.; Claborn, D.M.; Lawyer, P.; Florin, D.; Brown, G.C. New state records for Lutzomyia shannoni and Lutzomyia vexator. J. Med. Entomol. 2009, 46, 965-968.

7. Mann, R.S.; Kaufman, P.E.; Butler, J.F. A sand fly, Lutzomyia shannoni Dyar (Insecta: Diptera: Psychodidae: Phlebotomine). Available online: http://edis.ifas.ufl.edu/in797 (accessed on 13 November 2014).

8. Arevalo, J.; Ramirez, L.; Adaui, V.; Zimic, M.; Tulliano, G.; Miranda-Verástegui, C.; Lazo, M.; Loayza-Muro, R.; De Doncker, S.; Maurer, A.; et al. Influence of Leishmania (Viannia) species on the response to antimonial treatment in patients with American tegumentary leishmaniasis. J. Infect. Dis. 2007, 195, 1846-1851.

9. Goto, H.; Lindoso, J.A.L. Current diagnosis and treatment of cutaneous and mucocutaneous leishmaniasis. Exp. Rev. Anti-Infect. Ther. 2010, 8, 419-433.

10. Cragg, G.M.; Newman, D.J.; Snader, K.M. Natural products in drug discovery and development. J. Nat. Prod. 1997, 60, 52-60.

11. Newman, D.J.; Cragg, G.M. Natural products as sources of new drugs over the last 25 years. J. Nat. Prod. 2007, 70, 461-477.

12. Newman, D.J.; Cragg, G.M. Natural products as sources of new drugs over the years from 1981 to 2010. J. Nat. Prod. 2012, 75, 461-477.

13. Chan-Bacab, M.J.; Peña-Rodriquez, L.M. Plant natural products with leishmanicidal activity. Nat. Prod. Rep. 2001, 18, 674-688.

14. Rocha, L.G.; Almeica, J.R.G.S.; Macêdo, R.O.; Barbosa-Filho, J.M. A review of natural products with antileishmanial activity. Phytomedicine 2005, 12, 514-535.

15. Salem, M.M.; Werbovetz, K.A. Natural products from plants as drug candidates and lead compounds against leishmaniasis and trypanosomiasis. Curr. Med. Chem. 2006, 13, 2571-2598.

16. Sen, R.; Chatterjee, M. Plant derived therapeutics for the treatment of leishmaniasis. Phytomedicine 2011, 18, 1056-1069. 
17. Ogungbe, I.V.; Singh, M.; Setzer, W.N. Antileishmanial natural products from plants. Stud. Nat. Prod. Chem. 2012, 36, 331-382.

18. Schmidt, T.J.; Khalid, S.A.; Romanha, A.J.; Alves, T.M.A.; Biavatti, M.W.; Brun, R.; Da Costa, F.B.; de Castro, S.L.; Ferreira, V.F.; de Lacerda, M.V.G.; et al. The potential of secondary metabolites from plants as drugs or leads against protozoan neglected diseases-Part I. Curr. Med. Chem. 2012, $19,2128-2175$.

19. Schmidt, T.J.; Khalid, S.A.; Romanha, A.J.; Alves, T.M.A.; Biavatti, M.W.; Brun, R.; Da Costa, F.B.; de Castro, S.L.; Ferreira, V.F.; de Lacerda, M.V.G.; et al. The potential of secondary metabolites from plants as drugs or leads against protozoan neglected diseases-Part II. Curr. Med. Chem. 2012, 19, 2176-2228.

20. Setzer, M.C.; Setzer, W.N.; Jackes, B.R.; Gentry, G.A.; Moriarity, D.M. The medicinal value of tropical rainforest plants from Paluma, north Queensland, Australia. Pharmaceut. Biol. 2001, 39, $67-78$.

21. Setzer, M.C.; Moriarity, D.M.; Lawton, R.O.; Setzer, W.N.; Gentry, G.A.; Haber, W.A. Phytomedicinal potential of tropical cloudforest plants from Monteverde, Costa Rica. Rev. Biol. Trop. 2003, 51, 647-674.

22. Setzer, M.C.; Werka, J.S.; Irvine, A.K.; Jackes, B.R.; Setzer, W.N. Biological activity of rainforest plant extracts from far north Queensland, Australia. In Biologically Active Natural Products for the 21st Century, Williams, L.A.D. Ed.; Research Signpost: Trivandrum, India, 2006; pp. 21-46.

23. Sladowski, D.; Steer, S.J.; Clothier, R.H.; Balls, M. An improve MTT assay. J. Immunol. Meth. 1993, 157, 203-207.

24. Dutta, A.; Bandyopadhyay, S.; Mandal, C.; Chatterjee, M. Development of a modified MTT assay for screening antimonial resistant field isolates of Indian visceral leishmaniasis. Parasitol. Int. 2005, 54, 119-122.

25. Caio, E.; Lima, D.; Kaplan, M.A.C.; Nazareth, M.; Rossi-Bergmann, B. Selective effect of 2,6-dihydroxy-4-methoxychalcone isolated from Piper aduncum on Leishmania amazonensis. Antimicrob. Agent. Chemother. 1999, 43, 1234-1241.

26. Delorenzi, J.C.; Attias, M.; Gattass, C.R.; Andrade, M.; Rezende, C.; Da Cunha, A. Antileishmanial activity of an indole alkaloid from Peschiera australis. Antimicrob. Agent. Chemother. 2001, 45, 1349-1354.

27. Weniger, B.; Robledo, S.; Arango, G.J.; Deharo, E.; Aragón, R.; Muñoz, V.; Callapa, J.; Lobstein, A.; Anton, R. Antiprotozoal activities of Colombian plants. J. Ethnopharmacol. 2001, 78, 193-200.

28. Ndjakou, L.B.; Vonthron-Sénécheau, C.; Fongang, S.R.; Tantangmo, F.; Ngouela, S.; Kaiser, M.; Tsamo, E.; Anton, R.; Weniger, B. In vitro antiprotozoal activities and cytotoxicity of some selected Cameroonian medicinal plants. J. Ethnopharmacol. 2007, 111, 8-12.

29. Salomé Gachet, M.; Salazar Lecaro, J.; Kaiser, M.; Brun, R.; Navarrete, H.; Muñoz, R.A.; Bauer, R.; Schühly, W. Assessment of anti-protozoal activity of plants traditionally used in Ecuador in the treatment of leishmaniasis. J. Ethnopharmacol. 2010, 128, 184-197.

30. Morales, J.F. La familia Apocynaceae (Apocynoideae, Rauvolfioideae) en Guatemala. Darwiniana 2009, 47, 140-184. 
31. Walls, F.; Collera, O.; Sandoval, A.L. Alkaloids from Stemmadenia species-I: The alkaloids of S. donnell-smithii and S. galeottiana. Tetrahedron, 1958, 2, 173-182.

32. Soares, D.C.; Pereira, C.G.; Meireles, M.A.A.; Saraiva, E.M. Leishmanicidal activity of a supercritical fluid fraction obtained from Tabernaemontana catharinensis. Parasitol. Int. 2007, $56,135-139$.

33. Fernandez, L.S.; Sykes, M.L.; Andrews, K.T.; Avery, V.M. Antiparasitic activity of alkaloids from plant species of Papua New Guinea and Australia. Int. J. Antimicrob. Agents 2010, 36, 275-279.

34. Ogungbe, I.V.; Ng, J.D.; Setzer, W.N. Interactions of antiparasitic alkaloids with Leishmania protein targets: A molecular docking analysis. Future Med. Chem., 2013, 5, 1777-1799.

35. Chinchilla-Carmona, M.; Valerio-Campos, I.; Sánchez-Porras, R.; Bagnarello-Madrigal, V.; Martínez-Esquivel, L.; González-Paniagua, A.; Alpizar-Cordero, J.; Cordero-Villalobos, M.; Rodríguez-Chaves, D. Actividad contra Leishmania sp. (Kinetoplastida: Trypanosomatidae) de plantas en una Reserva Biológica de Costa Rica. Rev. Biol. Trop. 2014, 62, 1229-1240.

36. Filho, V.C.; Meyre-Silva, C.; Niero, R.; Bolda Mariano, L.N.; Gomes do Nascimento, F.; Farias, I.V.; Gazoni, V.F.; dos Santos Silva, B.; Giménez, A.; Gutierrez-Yapu, D.; et al. Evaluation of antileishmanial activity of selected Brazilian plants and identification of the active principles. Evid.-Based Complement. Altern. Med. 2013, doi:10.1155/2013/265025.

37. Alves Santos, K.K.; Rolón, M.; Vega, C.; Rojas de Arias, A.; Martins da Costa, J.G.; Melo Coutinho, H.D. Atividade leishmanicida in vitro de Eugenia uniflora e Momordica charantia. Rev. Ciên. Farm. Básic. Apl. 2013, 34, 47-50.

38. Braga, F.G.; Mouzada, M.L.M.; Fabri, R.L.; Matos, M.d.O.; Moreira, F.O.; Scio, E.; Coimbra, E.S. Antileishmanial and antifungal activity of plants used in traditional medicine in Brazil. J. Ethnopharmacol. 2007, 111, 396-402.

39. Rodrigues, K.A.d.F.; Amorim, L.V.; Guerra de Oliveira, J.M.; Dias, C.N.; Moraes, D.F.C.; Andrade, E.H.d.A.; Maia, J.G.S.; Carneiro, S.M.P.; Carvalho, F.A.d.A. Eugenia uniflora L. essential oil as a potential anti-Leishmania agent: Effects on Leishmania amazonensis and possible mechanisms of action. Evid.-Based Complement. Altern. Med. 2013, doi:10.1155/2013/279726.

40. Desrivot, J.; Waikedre, J.; Cabalion, P.; Herrenknecht, C.; Bories, C.; Hocquemiller, R.; Fournet, A. Antiparasitic activity of some New Caledonian medicinal plants. J. Ethnopharmacol. 2007, $112,7-12$.

41. Hui, W.H.; Li, M.M. Triterpenoids from two Mallotus species: A nor-triterpene and two new acids. Phytochemistry 1976, 15, 985-986.

42. Okpekon, T.; Yolou, S.; Gleye, C.; Roblot, F.; Loiseau, P.; Bories, C.; Grellier, P.; Frappier, F.; Laurens, A.; Hocquemiller, R. Antiparasitic activities of medicinal plants used in Ivory Coast. J. Ethnopharmacol. 2004, 90, 91-97.

43. Kaler, K.M.; Setzer, W.N. Seasonal variation in the leaf essential oil composition of Sassafras albidum. Nat. Prod. Commun. 2008, 3, 829-832.

44. Kennedy, J.E.; Davé, P.C.; Harbin, L.N.; Setzer, W.N. Allelopathic potential of Sassafras albidum and Pinus taeda essential oils. Allelopathy J. 2011, 27, 111-122. 
45. Monzote, L.; Alarcón, O; Setzer, W.N. Antiprotozoal activity of essential oils. Agric. Consp. Scient. 2012, 77, 167-175.

46. Mikus, J.; Harkenthal, M.; Steverding, D.; Reishling, J. In vitro effect of essential oils and isolated mono- and sesquiterpenes on Leishmania major and Trypanosoma brucei. Planta Med. 2000, 66, $366-368$.

47. Camargos, H.S.; Moreira, R.A.; Mendanha, S.A.; Fernandes, K.S.; Dorta, M.L.; Alonso, A. Terpenes increase the lipid dynamics in the Leishmania plasma membrane at concentrations similar to their $\mathrm{IC}_{50}$ values. PLoS ONE 2014, 9, doi:10.1371/journal.pone.0104429.

48. França, F.F.; Lago, E.L.; Marsden, P.D. Plants used in the treatment of leishmanial ulcers due to Leishmania (Viannia) braziliensis in an endemic area of Bahia, Brazil. Rev. Soc. Bras. Med. Trop. 1996, 29, 229-232.

49. González-Coloma, A.; Reina, M.; Sáenz, C.; Lacret, R.; Ruiz-Mesia, L.; Arán, V.J.; Sanz, J.; Martínez-Díaz, R.A. Antileishmanial, antitrypanosoma, and cytotoxic screening of ethnopharmacologically selected Peruvian plants. Parasitol. Res. 2012, 110, 1380-1392.

50. Ali, A.; Kiderlen, A.; Kolodziej, H. Lapachol and isomeric 5- and 8-hydroxy-2-(1'-hydroxyethyl) naphtho[2,3-b] furan-4,9-diones are effective antileishmanial constituents of Tabebuia avellanedae. Planta Med. 2010, 76, doi:10.1055/s-0030-1264769.

51. Bates, R.B.; Cai, S.; Cantor, R.S.; Carducci, M.D.; Irvine, A.K.; Jiorle, B.V.; Nakkiew, P.; Setzer, W.N.; Trinh, L.N. Agatholic acid. Acta Crystallogr. Sect. E 2003, E59, o97-o98.

52. Brophy, J.J.; Goldsack, R.J.; Forster, P.I. Composition of the leaf oils of the Australian species of Euodia and Melicope (Rutaceae). J. Essent. Oil Res. 2004, 16, 286-293.

53. Setzer, W.N.; Vogler, B.; Schmidt, J.M.; Petty, J.L.; Haber, W.A. Isolation of cupanioside, a novel cytotoxic and antibacterial long-chain fatty alcohol glycoside from the bark of Cupania glabra. Planta Med. 2005, 71, 686-688.

54. Peraza-Sánchez, S.R.; Cen-Pacheco, F.; Noh-Chimal, A.; May-Pat, F.; Simá-Polanco, P.; Dumonteil, E.; García-Miss, M.R.; Mut-Martín, M. Leishmanicidal evaluation of extracts from native plants of the Yucatan peninsula. Fitoterapia 2007, 78, 315-318.

55. Gachet, M.S.; Kunert, O.; Kaiser, M.; Brun, R.; Zehl, M.; Keller, W.; Muñoz, R.A.; Bauer, R.; Schuehly, W. Antiparasitic compounds from Cupania cinerea with activities against Plasmodium falciparum and Trypanosoma brucei rhodesiense. J. Nat. Prod. 2011, 74, 559-566.

56. De Mesquita, M.L.; Desrivot, J.; Bories, C.; Fournet, A.; de Paula, J.E.; Grellier, P.; Espindola, L.S. Antileishmanial and trypanocidal activity of Brazilian Cerrado plants. Mem. Inst. Oswaldo Cruz 2005, 100, 783-787.

57. Hazra, B.; Saha, S.K.; Ray, R.; Roy, D.K.; Sur, P.; Banerjee, A. Antiprotozoal activity of diospyrin towards Leishmania donovani promastigotes in vitro. Trans. Royal Soc. Trop. Med. Hygiene 1987, 81, 738-741.

58. Hazra, B.; Golenser, J.; Nechemiya, O.; Bhattacharyya, S.; Azzam, T.; Domb, A.; Frankenburg, S. Inhibitory activity of diospyrin derivatives against Leishmania major parasites in vitro. Indian J. Pharmacol. 2002, 34, 422-427.

59. Ray, S.; Hazra, B.; Mittra, B.; Das, A.; Majumder, H.K. Diospyrin, a bisnaphthoquinone: A novel inhibitor of type I DNA topoisomerase of Leishmania donovani. Mol. Pharmacol. 1998, 54, 994-999. 
60. Mukherjee, P.; Majee, S.B.; Ghosh, S.; Hazra, B. Apoptosis-like death in Leishmania donovani promastigotes induced by diospyrin and its ethanolamine derivative. Int. J. Antimicrob. Agent. 2009, 34, 596-601.

61. Ganapaty, S.; Thomas, P.S.; Karagianis, G.; Waterman, P.G.; Brun, R. Antiprotozoal and cytotoxic naphthalene derivatives from Diospyros assimilis. Phytochemistry 2006, 67, 1950-1956.

62. Mori-Yasumoto, K.; Izumoto, R.; Fuchino, H.; Ooi, T.; Agatsuma, Y.; Kusumi, T.; Satake, M.; Sekita, S. Leishmanicidal activities and cytotoxicities of bisnaphthoquinone analogues and naphthol derivatives from Burman Diospyros burmanica. Bioorg. Med. Chem. 2012, 20, 5215-5219.

63. Luize, P.S.; Tiuman, T.S.; Morello, L.G.; Maza, P.K.; Ueda-Nakamura, T.; Dias Filho, B.P.; Garcia Cortez, D.A.; Palazzo de Mello, J.C.; Nakamura, C.V. Effects of medicinal plant extracts on growth of Leishmania (L.) amazonensis and Trypanosoma cruzi. Rev. Bras. Ciên. Farm. 2005, 41, 85-94.

64. Takahashi, M.; Fuchino, H.; Satake, M.; Agatsuma, Y.; Sekita, S. In vitro screening of leishmanicidal activity in Myanmar timber extracts. Biol. Pharm. Bull. 2004, 27, 921-925.

65. Billo, M.; Fournet, A.; Cabalion, P.; Waikedre, J.; Bories, C.; Loiseau, P.; Prina, E.; Rojas de Arias, A.; Yaluff, G.; Fourneau, C.; et al. Screening of New Caledonian and Vanuatu medicinal plants for antiprotozoal activity. J. Ethnopharmacol. 2005, 96, 569-575.

66. Odonne, G.; Berger, F.; Stein, D.; Grenand, P.; Bourdy, G. Treatment of leishmaniasis in the Oyapock basin (French Guiana): A K.A.P. survey and analysis of the evolution of phytotherapy knowledge amongst Wayãpi Indians. J. Ethnopharmacol. 2011, 137, 1228-1239.

67. Memoona, A.; Amir, M.K.; Sultan, A.; Razia, P.; Sumera, P.; Lal, M.; Nisar, A. Evaluation of Nepeta laevigata, Nepeta kurramensis and Rhynchosia reniformis on antimalarial and antileishmanial activities. Int. J. Bioassays 2012, 1, 122-127.

68. Dosoky, N.S.; Stewart, C.D.; Setzer, W.N. Identification of essential oil components from Conradina canescens. Am. J. Essent. Oils Nat. Prod. 2014, 2, 24-28.

69. Machado, M.; Dinis, A.M.; Santos-Rosa, M.; Alves, V.; Salgueiro, L.; Cavaleiro, C.; Sousa, M.C. Activity of Thymus capitellatus volatile extract, 1,8-cineole and borneol against Leishmania species. Vet. Parasitol. 2014, 200, 39-49.

70. Nibret, E.; Wink, M. Trypanocidal and antileukaemic effects of the essential oils of Hagenia abyssinica, Leonotis ocymifolia, Moringa stenopetala, and their main individual constituents. Phytomedicine 2010, 17, 911-920.

(C) 2014 by the authors; licensee MDPI, Basel, Switzerland. This article is an open access article distributed under the terms and conditions of the Creative Commons Attribution license (http://creativecommons.org/licenses/by/4.0/). 